\title{
Analysis of Large-Signal Output Capacitance of Transistors using Sawyer-Tower Circuit
}

\author{
Nirmana Perera, Student Member, IEEE, Georgios Kampitsis, Member, IEEE, Remco Van Erp, Jessy Ançay, \\ Armin Jafari, Mohammad Samizadeh Nikoo, Member, IEEE, and Elison Matioli, Member, IEEE
}

\begin{abstract}
A detailed analysis on the Sawyer-Tower method used in the measurement of large-signal output capacitance $\left(C_{0}\right)$ of power transistors is presented, followed by important design recommendations to obtain accurate results. Key factors affecting the proper implementation of the technique, such as power amplifier characteristics, load slew-rate, reference capacitor $\left(C_{\text {ref }}\right)$ and reverse conduction of the device are addressed, with accompanying simulation and experimental results for $\mathrm{Si}$, $\mathrm{SiC}$ and GaN devices. A thorough investigation on the selection of $C_{\text {ref }}$ is presented, with a new equation to correctly determine its value for a given voltage swing and output capacitance range of the Device Under Test (DUT). We report that the SawyerTower circuit impose the DUT to enter steady-state reverse conduction under certain conditions, leading to charge-voltage $(Q V)$ hysteresis patterns unrelated to $C_{0}$. Our analysis reveals that the origin of this phenomenon is related to DUT's leakage current, and that it could be minimized by proper selection of the excitation frequency. This work intends to provide an effective guide on designing and using the Sawyer-Tower circuit and to induce further scientific insight in characterizing $C_{0}$.
\end{abstract}

Index Terms- $C_{0}, C_{\text {oss }}, E_{\text {diss }}$, Sawyer-Tower, output capacitance, large-signal losses, soft-switching losses, WBG devices.

\section{INTRODUCTION}

With the emergence of Wide-Band-Gap (WBG) semiconductor devices, high-frequency power converters have gained increased attention [1]-[8]. However, the operation of power electronics in the $\mathrm{MHz}$ range is influenced by the power losses associated with device output capacitance, $C_{\mathrm{o}}$ [9]. The observation of hysteresis losses in charging-discharging $C_{\mathrm{o}}$ of Si Super-Junction (SJ) MOSFETs [10]-[13], and WBG devices [13]-[16], initiated increased focus on device $C_{\mathrm{o}}$ and its large-signal behaviour, as the data-sheet provided small-signal capacitance, $C_{\text {oss }}$, is incapable of explaining such behaviour.

One of the main techniques adapted to observe the largesignal behaviour of $C_{\mathrm{o}}$ is the Sawyer-Tower circuit [16][20]. The circuit consists of a signal generator, a high-voltage amplifier, a fixed linear reference capacitor, $C_{\text {ref }}$, and the Device Under Test (DUT). The operation of the circuit is heavily dependent on all its parameters. For instance, the output resistance and the current limit of the high-voltage amplifier could distort the excitation signal applied on the DUT. The characteristics of $C_{\text {ref }}$ depends on the dc-bias voltage and the excitation frequency, $f_{\mathrm{e}}$, applied on it, and could compromise

This work was supported in part by the Swiss Office of Energy (SFOE) Grant Numbers SI501887-01 (MEPCO) and SI501568-01. The authors are with the Power and Wide-Band-Gap Electronics Research Laboratory, École Polytechnique Fédérale de Lausanne, 1015 Lausanne, Switzerland. (e-mail: nirmana.perera@epfl.ch, elison.matioli@epfl.ch)
TABLE I

IMPORTANT SYMBOLS AND ABBREVIATIONS USED IN THE PAPER

\begin{tabular}{|c|c|}
\hline Symbol & Description \\
\hline$C_{\mathrm{o}}$ & output capacitance of the Device Under Test (DUT) \\
\hline$C_{\text {oss }}$ & small-signal output capacitance \\
\hline$C_{\text {ref }}$ & reference capacitance \\
\hline$C_{\text {eq }}$ & equivalent load capacitance \\
\hline$Q_{\mathrm{o}}$ & output charge of the DUT \\
\hline$Q_{\text {oss }}$ & small-signal output charge of the DUT \\
\hline$q_{\mathrm{REF}}, Q_{\mathrm{REF}}, q_{\mathrm{ref}}$ & total, dc and ac components of $C_{\text {ref }}$ charge \\
\hline$\Delta Q_{+}$ & positive dc charge in $C_{\text {ref }}$ due to leakage of the DUT \\
\hline$E_{\text {diss }}$ & energy dissipated in $C_{\mathrm{o}}$ during a charge-discharge cycle \\
\hline$v_{\mathrm{S}}$ & signal generator output voltage \\
\hline$v_{\mathrm{A}}$ & voltage amplifier output voltage \\
\hline $\begin{array}{l}v_{\mathrm{IN}}, v_{\text {in }} \\
V_{\mathrm{p}}\end{array}$ & $\begin{array}{l}\text { total and ac components of the input voltage to the load } \\
\text { peak value of } v_{\text {in }}\end{array}$ \\
\hline$v_{\mathrm{DS}}, V_{\mathrm{DS}}, v_{\mathrm{ds}}$ & total, dc and ac components of drain-source voltage \\
\hline$V_{\text {DS-max }}, V_{\text {DS-min }}$ & maximum and minimum of large-signal $v_{\mathrm{ds}}$ swing \\
\hline$v_{\mathrm{REF}}, V_{\mathrm{REF}}, v_{\mathrm{ref}}$ & total, dc and ac components of $C_{\text {ref }}$ voltage \\
\hline$V_{\text {ref+ }}, V_{\text {ref- }}$ & peak values of positive and negative swings of $v_{\text {ref }}$ \\
\hline$v_{\mathrm{GS}}$ & gate-source voltage \\
\hline$V_{\text {bus }}$ & bus (or dc-link) voltage \\
\hline$-V_{\mathrm{FW}}$ & dc voltage drop during reverse conduction of the DUT \\
\hline$V_{\text {BIAS }}$ & steady-state dc bias voltage in $C_{\text {ref }}$ \\
\hline$i_{C_{\mathrm{o}}}$ & total-instantaneous current through $C_{\mathrm{o}}$ of the DUT \\
\hline$i_{\mathrm{LEAK}}, I_{\mathrm{LEAK}-\max }$ & total and maximum leakage current of the DUT \\
\hline$i_{\mathrm{LOAD}}$ & total-instantaneous load current \\
\hline$I_{\text {limit }}$ & current limit of the voltage amplifier \\
\hline$G, R_{\mathrm{o}}$ & gain and output resistance of the voltage amplifier \\
\hline$f_{\mathrm{e}}$ & frequency of the ac excitation signal \\
\hline$S . R .\left.\right|_{\mathrm{exc}}$ & slew-rate of the amplified ac excitation signal \\
\hline$S . R .\left.\right|_{\mathrm{amp}} ^{\mathrm{coc}}$ & maximum limit of the slew-rate of voltage amplifier \\
\hline$S . R .\left.\right|_{\text {dominant }}$ & dominant slew-rate of the equivalent load \\
\hline rate $_{1}$ & rate of change of voltage across $C_{\mathrm{eq}}$ due to $I_{\text {limit }}$ \\
\hline rate $_{2}$ & voltage rise-rate of $C_{\mathrm{eq}}$ subjected to $R C$ limitations \\
\hline
\end{tabular}

the measurement accuracy. A DUT with large $C_{\text {oss }}$ could result in a low-impedance load that could exceed amplifier's loading capabilities. Neglecting the effects of these parameters on the circuit inevitably lead to measurement inaccuracies and false conclusions. Therefore, a thorough investigation on the technical aspects of the method is essential.

This work presents a detailed discussion on the SawyerTower technique for large-signal output capacitance characterization, addressing key factors affecting the accuracy and the range of measurements. Two new equations are given to correctly express output charge, $Q_{\mathrm{o}}$, versus $v_{\mathrm{DS}}(Q V)$, and to select $C_{\text {ref }}$ in terms of required voltage swings. It is proved that the Sawyer-Tower circuit (under certain conditions) in steadystate could make the DUT enter reverse conduction at the negative peak of the input signal: this could compromise the basic assumptions of the method. The paper is structured as follows. Section II provides important background on large-signal $C_{\mathrm{o}}$ behaviour and motivation for the work. Section III explains the 
operation of the Sawyer-Tower circuit. Section IV addresses the aforementioned key technical aspects. Sections V and VI discuss design recommendations and conclusions.

\section{Motivation}

In this section, the importance of large-signal $C_{\mathrm{o}}$ and $Q_{\mathrm{o}}$ measurements are discussed with practical examples to provide motivation for the presented work. The Sawyer-Tower method is compared with existing large-signal measurement methods.

\section{A. Small-Signal vs Large-Signal Output Capacitance}

To estimate $C_{\mathrm{o}}$-related losses, conventionally, the device data sheets provide a small-signal output capacitance ${ }^{1}, C_{\mathrm{oss}}$, that is measured by applying a small ac perturbation (limited to $10-200 \mathrm{mV}$ ) over a dc bias on the DUT (with $v_{\mathrm{GS}}=0$ ) [24]. Unlike the real operating conditions in power electronic circuits, these measurements never subject $C_{\mathrm{o}}$ to a large voltage swing. Recent research shows that data-sheet based $C_{\text {oss }}$ curves fail to accurately estimate losses related to $C_{\mathrm{o}}[17]$, [25]. Another limitation of this method is that the $C_{\text {oss }}$ value is dependent on the model used in the measurement tool for the extraction of the capacitance from impedance [26], [27].

On the other hand, large-signal measurements generally estimate $C_{\mathrm{o}}$ (or more often, $Q_{\mathrm{o}}$ ) of a power transistor by subjecting the device to large voltages, for instance, between $0 \mathrm{~V}$ and bus voltage ( $\left.V_{\text {bus }}\right)$, an approach that much better emulates the charge-discharge behaviour of $C_{\mathrm{o}}$ in an actual circuit [16], [17], [28]. Large-signal $C_{\mathrm{o}}$ is then defined as $i_{C_{\mathrm{o}}}=C_{\mathrm{o}}\left(v_{\mathrm{DS}}\right) \cdot d v_{\mathrm{DS}} / d t$, from which we deduce

$$
C_{\mathrm{o}}\left(v_{\mathrm{DS}}\right)=d Q_{\mathrm{o}}\left(v_{\mathrm{DS}}\right) / d v_{\mathrm{DS}} .
$$

This definition should be used to avoid a common confusion where a non-linear capacitance is defined by the linear equation $C_{\mathrm{o}}\left(v_{\mathrm{DS}}\right)=Q_{\mathrm{o}}\left(v_{\mathrm{DS}}\right) / v_{\mathrm{DS}}$ that fails to capture the device's large-signal variation of its charges [17], [29]. Acknowledging the fact that both large-signal charge and capacitance are functions of $v_{\mathrm{DS}}$, for the remainder of the paper, we use the simple notations $C_{\mathrm{o}}\left(v_{\mathrm{DS}}\right)=C_{\mathrm{o}}$ and $Q_{\mathrm{o}}\left(v_{\mathrm{DS}}\right)=Q_{\mathrm{o}}$.

The difference between large and small-signal curves, and hence the severity of the error in actual $Q_{\mathrm{o}}$ (or $C_{\mathrm{o}}$ ) and related losses, varies based on the device type. The implications of this in real converter applications are twofold, depending if the device is hard switched or soft switched. If the device is hard switched, for instance in a double-pulse test circuit, the total $C_{\mathrm{o}}$-related losses occur first in charging $C_{\mathrm{o}}$ through the available circuit path, and then discharging the charge stored in $C_{\mathrm{o}}$ through the device channel itself [30]. The resulting loss is given by the product $\left.Q_{\mathrm{o}}\right|_{V_{\text {bus }}} \cdot V_{\text {bus }}$. Therefore, the error in the losses is directly related to the estimated $Q_{0}$ value at a given $V_{\text {bus. }}$ Fig. 1a shows an example for a $\mathrm{Si}-\mathrm{SJ}$ transistor,

\footnotetext{
${ }^{1}$ The following notation is used to refer to a device's output-capacitancerelated parameters: output capacitance, $C_{\mathrm{o}}$; output charge, $Q_{\mathrm{o}}$; energy stored in the output capacitance, $E_{\mathrm{o}}$ [21]. The corresponding small-signal parameters are denoted, using the conventional method used in device data sheets, as $C_{\mathrm{oss}}$. $Q_{\text {oss }}$ and $E_{\text {oss }}[22]$, [23].
}

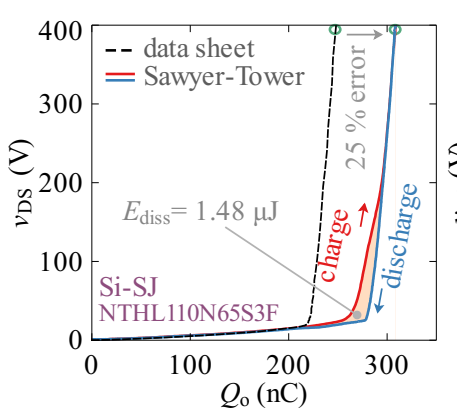

(a)

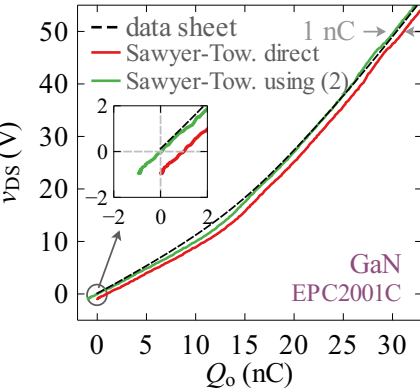

(b)
Fig. 1. Large-signal $Q_{\mathrm{o}}$ vs $v_{\mathrm{DS}}$ curves obtained from the Sawyer-Tower circuit at $100 \mathrm{kHz}$ for two devices, where the dashed black lines show the small-signal $Q_{\text {oss }}$ estimated based on data-sheet $C_{\text {oss }}$ curves. (a) The Si-SJ device $(650 \mathrm{~V})$ exhibits a large difference in small and large-signal curves, with $Q_{\mathrm{o}}$ at $400 \mathrm{~V}$ showing a $25 \%$ increase in the large-signal results. With distinct charging-discharging paths (solid red and blue lines respectively), the $\mathrm{Si}-\mathrm{SJ}$ device shows a considerable hysteresis loss of $E_{\mathrm{diss}}=1.48 \mu \mathrm{J}$. (b) A $100-\mathrm{V}$ GaN device with different small and large-signal curves, but with negligible hysteresis: only the charge path is shown in green as the discharge path coincides with it. The red line shows the direct Sawyer-Tower result without using (2) (see Section III).

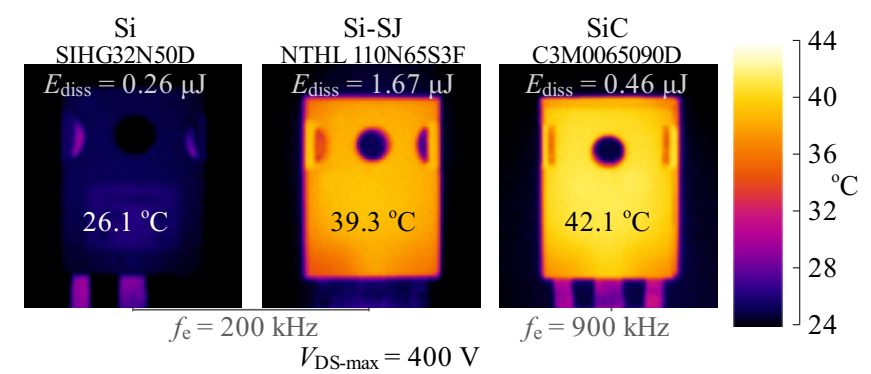

Fig. 2. Thermal images showing the temperature rise of three devices ( $\mathrm{Si}$, $\mathrm{Si}-\mathrm{SJ}$ and $\mathrm{SiC}$ ) with different $E_{\text {diss }}$ values (estimated using the Sawyer-Tower circuit). The devices (at $v_{\mathrm{GS}}=0 \mathrm{~V}$ ) have the same hardware package (TO-247) and were excited sinusoidally in the Sawyer-Tower circuit arrangement at 400 $\mathrm{V}$. The observed losses are not possible to be calculated based on data sheets, and ideally, these devices should not dissipate any power as charging and discharging of $C_{\mathrm{o}}$ is assumed to be lossless. The observed power dissipation reveals the need for a proper $C_{\mathrm{o}}$ characterization.

where small-signal $Q_{\text {oss }}$ value varies by $25 \%$ in comparison to the large-signal value, resulting in a significant error in hardswitched losses. On the other hand, Fig. 1b shows a case for a GaN device, where the large-signal $Q_{\mathrm{o}}$ curve (solid green line) shows less deviation from the data-sheet curve, with negligible hysteresis at $100 \mathrm{kHz}$.

If the device $C_{\mathrm{o}}$ is resonantly charged and discharged with soft-switching conditions, based on the data-sheet curves, no $C_{\mathrm{o}}$-related loss should occur [16]. However, the $Q_{\mathrm{o}}$ vs $v_{\mathrm{DS}}$ curves of the Si-SJ device in Fig. 1a clearly reveals a difference in the charge-discharge paths, resulting in a hysteresis loss, $E_{\text {diss }}$ [20]. Fig. 2 shows three devices with similar hardware packages that were excited with a large-signal sinusoidal signal with a $400-\mathrm{V}$ peak voltage. The $\mathrm{Si}$ and $\mathrm{Si}-\mathrm{SJ}$ devices were excited at $200 \mathrm{kHz}$. The Si-SJ device exhibits a significant temperature rise, hence much larger power dissipation $\left(P_{\text {diss }}=\right.$ $E_{\text {diss }} \cdot f_{\mathrm{e}}$ ) compared to the $\mathrm{Si}$ device. This is due to relatively large $(1.67 \mu \mathrm{J}>0.26 \mu \mathrm{J}) E_{\text {diss }}$ of the Si-SJ device. Although the $\mathrm{SiC}$ device is switched at a much higher frequency $(4.5$ times higher), compared to the other two devices, it only shows a temperature $3{ }^{\circ} \mathrm{C}$ higher compared to the $\mathrm{Si}-\mathrm{SJ}$ device: this 
is due to $\mathrm{SiC}$ device's lower $E_{\text {diss }}$ value of $(0.46 \mu \mathrm{J}<1.67 \mu \mathrm{J})$. These results show the importance of the large-signal $Q_{\mathrm{o}}$ vs $v_{\text {DS }}$ measurements in predicting both hard and soft-switching losses, that are not possible to estimate based on data-sheet based small-signal $C_{\text {oss }}$ (or $Q_{\text {oss }}$ ) curves.

\section{B. Measurement Techniques of Large-Signal $C_{o}$ and $Q_{o}$}

The Sawyer-Tower technique has traditionally been used for ferroelectric dielectric material characterization [19]; and now has been adapted to characterize large-signal $C_{\mathrm{o}}$ of $\mathrm{Si}$, $\mathrm{Si}-\mathrm{SJ}, \mathrm{SiC}$ and $\mathrm{GaN}$ power transistors [16]-[18], [20], and very recently of $\mathrm{SiC}$ power diodes [15]. It initially obtains the device's output charge characteristic ( $Q_{\mathrm{o}}$ vs $\left.v_{\mathrm{DS}}\right)$ by applying a large excitation voltage, and subsequently, $C_{\mathrm{o}}$ is obtained by taking the derivative of $Q_{\mathrm{o}}$ with respect to $v_{\mathrm{DS}}$.

The Sawyer-Tower technique provides several distinct advantages for $C_{\mathrm{o}}$ characterization. The DUT (gate and source shorted) and a reference capacitor are the only two electronic devices involved: no external components such as inductors, active switches, gate drivers or control circuitry are required. Only two voltage measurements are involved ( $v_{\mathrm{IN}}$ and $v_{\mathrm{REF}}$ in Fig. 3a): this allows the method to be very accurate even at lower Very-High-Frequency (VHF) levels as there are no current measurements involved, which are prone to higher inaccuracies. The losses in the circuit are only due to $Q_{\mathrm{o}}$ hysteresis losses (Section IV-F discusses validity of this): no conduction or any other external losses exist, allowing direct evaluation of $E_{\text {diss }}$ by thermal measurements. A large range of voltage-swings across $v_{\text {DS }}$ can be achieved: if the voltage is limited due to the amplifier's output voltage rating, a simple High-Frequency (HF) transformer can be used to boost the voltage output, provided that the amplifier's output power capability is not exceeded for the given $f_{\mathrm{e}}$. Moreover, the method can easily perform frequency sweeps, by changing the signal-generator output frequency $\left(=f_{\mathrm{e}}\right)$.

However, the Sawyer-Tower method has some technical limitations. The maximum voltage swing for a given $f_{\mathrm{e}}$ (even with a HF transformer) is confined by the voltage amplifier [20], [28], because the gain of the amplifier degrades with increasing $f_{\mathrm{e}}$ as the power output capability of the amplifier is limited. The response due to different excitation signal types offer additional details about a device's $C_{\mathrm{o}}$ [16]: for instance, triangular waveforms allow to observe the response due to a constant $d v / d t$ excitation, whereas pulsed excitation creates a very high $d v / d t$ condition. Although near sinusoidal waveforms could be applied at higher frequencies, the application of pulsed waveforms is limited by the bandwidth of the voltage amplifier and the value of the equivalent load capacitance, $C_{\mathrm{eq}}$.

Several alternative methods exist for large-signal $Q_{\mathrm{o}}$ (or $C_{\mathrm{o}}$ ) estimation. A nonlinear-resonance method relies upon the resonance between a pre-calibrated inductor and the device $C_{\mathrm{o}}$ [28]. The method only requires a low-voltage dc source as the input, and therefore, eliminates the need for a high-voltage high-bandwidth amplifier. Since the DUT is switched to generate the resonant pulse, the method requires gate driving circuitry and external control signals. Furthermore, it is necessary

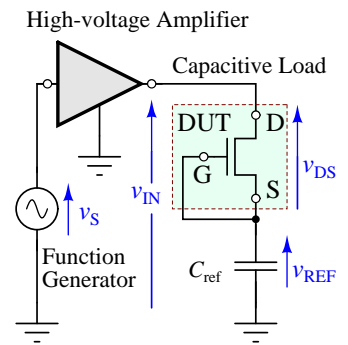

(a)

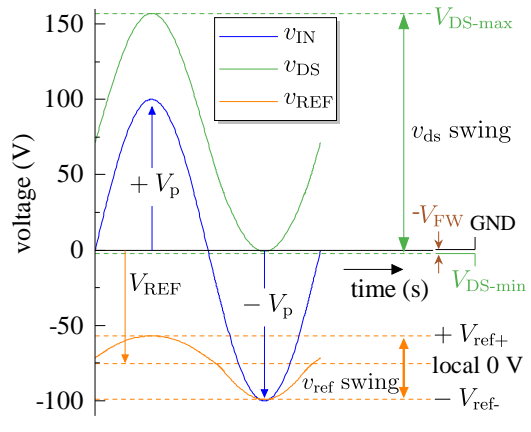

(b)
Fig. 3. (a) The Sawyer-Tower circuit, and (b) example of distribution of voltage waveforms in steady state. The local $0 \mathrm{~V}$ indicates the dc-level $\left(V_{\mathrm{REF}}\right)$ of $v_{\mathrm{REF}}$, upon which its ac component $v_{\text {ref }}$ varies.

to use different inductors for frequency sweeps. A modified version of the Sawyer-Tower circuit with improved bandwidth capabilities [13], involves a switched half-bridge arrangement (as a large-signal trapezoidal source) and an external LC component. Pure thermal/calorimetric measurements provide another way of large-signal $C_{\mathrm{o}}$ loss measurement. However, this only gives an estimation for losses at different $v_{\mathrm{DS}}$ values, and therefore fails to deliver $C V$ or $Q V$ patterns of the DUT, that are instrumental in understanding large-signal $C_{\mathrm{o}}$ or $Q_{\mathrm{o}}$ dependence on voltage. In addition, at lower power dissipation levels, the accuracy of this method is compromised [20]. In another method, a soft-switched H-bridge configuration is used [14], with a DC voltage source, two DC chokes and a load inductance, and three dc capacitors. The total losses are estimated with a calorimetric approach, where the separation of $C_{\mathrm{o}}$ losses from the total losses is prone to measurement inaccuracies in several stages. Also, the method does not deliver any large-signal $C V$ or $Q V$ patterns.

Although the Sawyer-Tower technique is based on a simple circuit, many factors could affect its valid operating range and subsequent measurements. And discourse on its proper implementation is limited in the technical literature. Recent research on the topic employ the Sawyer-Tower technique [16]-[18], and its variations [13], to demonstrate the difference between large and small-signal $C_{\mathrm{oss}}$ curves, however, an indepth explanation of the circuit operation and its limitations is not given. The recent work in [20] addresses some details of the circuit such as the reference capacitor selection and the body-diode operation to a certain extent. Nevertheless, to the best of our knowledge, an in-depth analysis of the SawyerTower technique for $C_{\mathrm{o}}$ measurement is not available in the literature. Our analysis in the next sections reveal important information about the practical operation of the circuit.

\section{OPERATION OF THE SAWYER-TOWER CIRCUIT}

The Sawyer-Tower circuit, shown in Fig. 3a, results in the steady-state voltage waveforms shown in Fig. 3b. The fundamental result of this method is a $Q_{\mathrm{o}}$ vs $v_{\mathrm{DS}}$ curve extracted from measured $v_{\mathrm{REF}}$ and $v_{\mathrm{DS}}$ data.

To obtain accurate results, a detailed analysis of the circuit is required. We consider a generic field-effect power transistor 
as the DUT whose gate and source terminals are shorted to remove the effects of gate capacitance, $C_{\mathrm{GS}}$, from the circuit. Therefore, the only active part of the DUT is its $C_{\mathrm{o}}$. The DUT is connected in series to a linear capacitor $C_{\text {ref }}$ to form an equivalent load capacitance $C_{\text {eq }}=C_{\mathrm{o}} \cdot C_{\text {ref }} /\left(C_{\mathrm{o}}+C_{\text {ref }}\right) . C_{\text {eq }}$ is subjected to an input voltage $v_{\text {IN }}$ created by amplifying a lowvoltage signal $v_{\mathrm{S}}$ with an excitation frequency of $f_{\mathrm{e}}$. In steady state, a dc-bias $\left(V_{\mathrm{REF}}\right)$ is built across $C_{\text {ref }}$, that corresponds to a dc charge, $Q_{\mathrm{REF}}$ [16]. Therefore, $v_{\mathrm{IN}}$ results only in an ac charge variation on $C_{\text {ref }}, q_{\text {ref }}=C_{\text {ref }} \cdot v_{\text {ref }}$, in steady state.

Since the DUT and $C_{\text {ref }}$ are in series, the same current flows through them in steady state, leading to equal charge variations: and hence, $Q_{\mathrm{o}} \propto C_{\text {ref }} \cdot v_{\text {ref }}$. However, the direct use of the expressions $Q_{\mathrm{o}}=C_{\text {ref }} \cdot v_{\text {ref }}$ and $Q_{\mathrm{o}}=C_{\text {ref }} \cdot v_{\mathrm{REF}}$, found in the literature [16], [17] could lead to inaccurate estimations, as they do not provide the complete behaviour of $Q_{\mathrm{o}}$ vs $v_{\mathrm{DS}}$ variation. The first does not take into account the zero baselined variation for $Q_{\mathrm{o}}$, while the latter incorporates the dccharge within $C_{\text {ref }}$. To address this problem, we introduce (2):

$$
\left.Q_{\mathrm{o}}\right|_{v_{\mathrm{DS}}}=C_{\text {ref }}\left(v_{\text {ref }}-\left.v_{\text {ref }}\right|_{v_{\mathrm{DS}}=0}\right),
$$

which takes into account the finite reverse voltage of the DUT: the term $\left.v_{\text {ref }}\right|_{v_{\mathrm{DS}}=0}$ ensures that $Q_{\mathrm{o}}=0$ when $v_{\mathrm{DS}}=0$. An example is shown in Fig. 1b for a GaN device, where the red line shows the $Q V$ curve obtained directly from the SawyerTower circuit: the zoomed inset reveals that $v_{\mathrm{DS}}<0$ when $Q_{\mathrm{o}}=0$. By adjusting the results using (2), the $Q V$ curve passes through the origin (solid green line), improving the accuracy of the measurement by $3.5 \%$ at $50 \mathrm{~V}$.

\section{Practical Considerations on the Circuit}

The Sawyer-Tower setup is a sensitive circuit that can be affected by several parameters of the equipment used and system parasitics. More importantly, no consideration is given in the literature on how the range and behaviour of $C_{\mathrm{o}}$ affect the operation of the entire circuit. These factors are analysed and explained through an experimental setup (listed in Table II), and the detailed circuit in Fig. 4.

\section{A. High-Voltage Amplifier and Equivalent Load}

A high-voltage amplifier is required to boost the excitation signal (from a signal generator) to test the devices up to their rated voltages (e.g. $600 \mathrm{~V}$ ). These amplifiers have two important characteristics that could affect the proper operation of the Sawyer-Tower circuit: 1) Current Limit, $I_{\text {limit }}$, and 2) finite Output Resistance, $R_{0}$. To study these effects independently, we assume the following conditions:

- a sinusoidal excitation signal $v_{\mathrm{S}}=V_{\mathrm{s}} \sin \left(\omega_{\mathrm{e}} t\right)$;

- ideal $C_{\text {eq }}$ with an infinite parallel resistance;

- output slew-rate of the amplifier (hardware-limited), $S . R .\left.\right|_{\mathrm{amp}}$, is larger than the slew-rate of the amplified $v_{\mathrm{S}}$, S.R. $\left.\right|_{\mathrm{exc}}=G \cdot 2 \pi f_{\mathrm{e}} V_{\mathrm{s}}$. (see Fig. 4).

$$
S . R .\left.\right|_{\mathrm{amp}} \geq S .\left.R \cdot\right|_{\mathrm{exc}}
$$

TABLE II

LIST OF EQUIPMENT USED FOR EXPERIMENTAL ANALYSIS

\begin{tabular}{lll}
\hline Name & Manufacturer & Description \\
\hline B1505A & Keysight & Power device analyser / Curve tracer \\
E4990A & Keysight & 50-MHz impedance analyser \\
33600A & Keysight & Trueform waveform generator \\
WMA-300 & Falco Systems & 5-MHz high-voltage amplifier \\
MDO3104 & Tektronix & Mixed domain 1-GHz (5 GS/s) oscilloscope \\
\hline
\end{tabular}

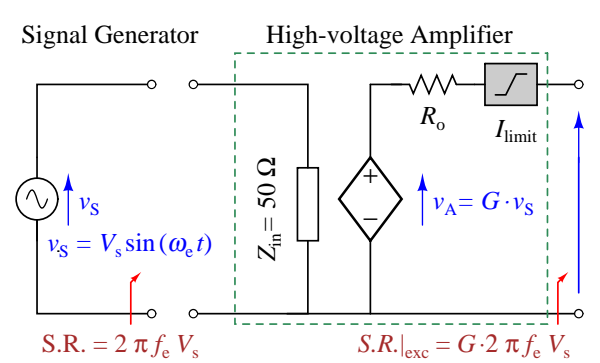

Capacitive Load

Fig. 4. Detailed Sawyer-Tower circuit highlighting slew-rates at each interface; amplifier output resistance, $R_{0}$, and current limit, $I_{\text {limit }}$; and the DUT where, $C_{\mathrm{o}}=C_{\mathrm{GD}}+C_{\mathrm{DS}}$.

These two factors are directly related to the rate of change of load voltage, and therefore, could result in voltage distortions if overlooked. $I_{\text {limit }}$ is a practical limit in commercial amplifiers and defines the maximum current through the load. Then the change in rate of voltage across $C_{\mathrm{eq}}$ is limited as given in (4).

$$
\text { rate }_{1}=\frac{d v}{d t}=\frac{I_{\text {limit }}}{C_{\mathrm{eq}}}
$$

The amplifier's $R_{\mathrm{o}}$ determines the $R C$ time constant for the load and results in the following relation:

$$
\text { rate }_{2}=\frac{V_{\mathrm{p}}}{4 R_{\mathrm{o}} C_{\mathrm{eq}}} .
$$

where $V_{\mathrm{p}}$ is the peak of the ac signal $v_{\text {in }}$ applied to the load. Here, we have considered four time constants to reach the maximum load voltage. Both of these rates can limit the full propagation of the amplifier output $v_{\mathrm{A}}$ to the load.

- if rate $_{2}>$ rate $_{1}$, rate $_{1}$ becomes dominant and the maximum load slew-rate is determined by $I_{\text {limit }}$ and $C_{\text {eq }}$. At the same time, if S.R. $\left.\right|_{\mathrm{exc}}>$ rate $_{1}$, the load can't follow the input: $v_{\mathrm{IN}}$ becomes distorted as $I_{\text {limit }}$ introduces a non-linearity to the circuit.

- if rate $_{1}>$ rate $_{2}$, the resultant load slew-rate is limited by $R_{\mathrm{o}}, V_{\mathrm{p}}$ and $C_{\mathrm{eq}}$. If $S . R .\left.\right|_{\mathrm{exc}}>$ rate $_{2}$, the load will follow the input voltage shape, but with a gain reduction due to $R C$ limitations.

These distortions are more pronounced when DUTs with large $C_{\text {oss }}$ values are tested.

\section{B. Effects of $C_{\mathrm{oss}}$ and $C_{\mathrm{ref}}$}

We base the following analysis on the small-signal output capacitance $C_{\mathrm{oss}}$. For all commercial power transistors, $C_{\mathrm{oss}}$ is a monotonically decreasing function of the applied $v_{\mathrm{DS}}$. Especially, in the "low $v_{\text {DS }}$ range" (see Fig. 5), it is significantly larger (even an order of magnitude) than in the large $v_{\mathrm{DS}}$ range. 


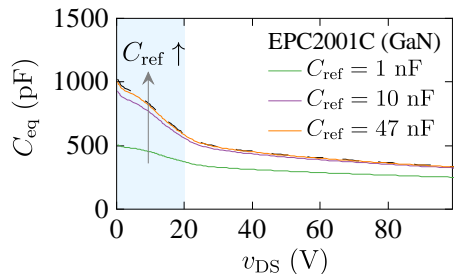

(a)

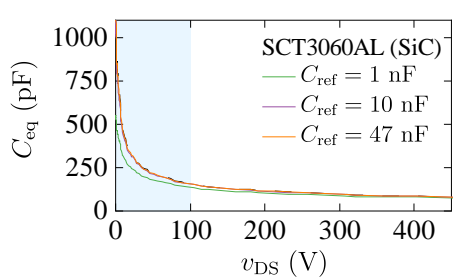

(c) (b)

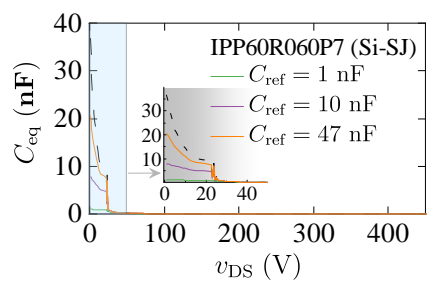

(d)

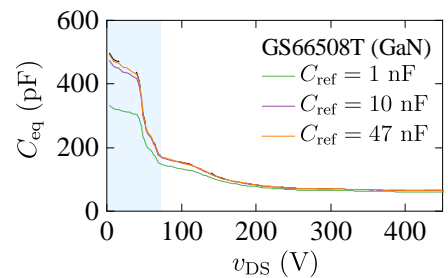

Fig. 5. $C_{\text {eq }}$ vs $v_{\text {DS }}$ curves of (a) EPC2001C $(\mathrm{GaN})$, (b) GS66508T $(\mathrm{GaN})$ (c) SCT3060AL (SiC), and (d) IPP60R060P7 (Si-SJ) transistors, for different $C_{\text {ref }}$ values. The dashed black lines show the data-sheet $C_{\text {oss }}$ curves. The shaded blue area highlights the "low $v_{\mathrm{DS}}$ region".

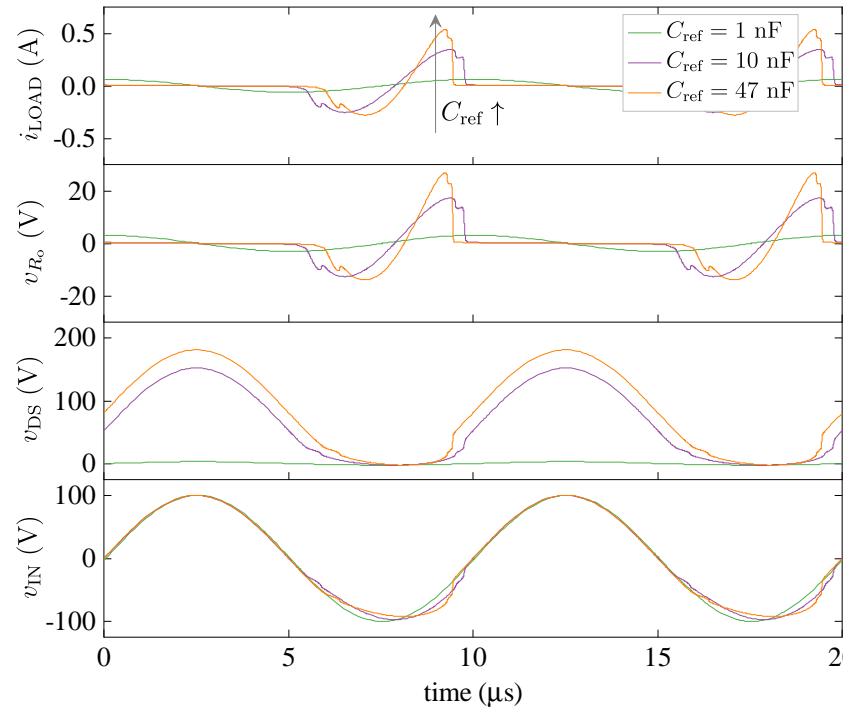

Fig. 6. LTspice simulation results showing the effects of having a large $C_{\mathrm{oss}}$ value in the low $v_{\mathrm{DS}}$ range, for $f_{\mathrm{e}}=100 \mathrm{kHz}$. The DUT is a Si-SJ MOSFET (IPP60R060P7) with $\left.C_{\mathrm{Oss}}\right|_{v_{\mathrm{DS}}=0} \approx 40 \mathrm{nF}$. The distortion in $v_{\mathrm{IN}}$ is intensified with increasing $C_{\text {ref }}$ as $Z_{\text {load }}$ further decreases.

Thus, the load impedance $\left(Z_{\text {load }}=1 / j \omega_{\mathrm{e}} C_{\text {eq }}\right)$ reduces greatly in the low $v_{\mathrm{DS}}$ range and results in the following implications:

1) $v_{\mathrm{IN}}$ gets distorted at the bottom of its negative half cycle (where the low $v_{\text {DS }}$ range occurs) as a higher voltage drops across $R_{0}$, clearly depicted in Fig. 6.

2) the load current can surpass $I_{\text {limit }}$ and alter $v_{\mathrm{IN}}$.

3) exceeding the amplifier's power capability at large $f_{\mathrm{e}}$ values, due to increased load current.

To prevent any signal distortion, a proper $C_{\text {ref }}$ value should be selected. As can be seen from Fig. 6, the lower the value of $C_{\text {ref }}$, the lower the distortion. However, excessive reduction of $C_{\text {ref }}$ reduces the available share for the $v_{\mathrm{DS}}$ swing (as the

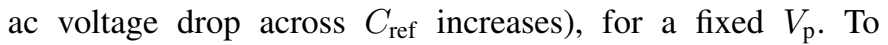
experimentally support this analysis, Fig. 7 shows $v_{\text {IN }}$ for a Si-SJ MOSFET for different $C_{\text {ref }}$ and $f_{\mathrm{e}}$ values. For the case
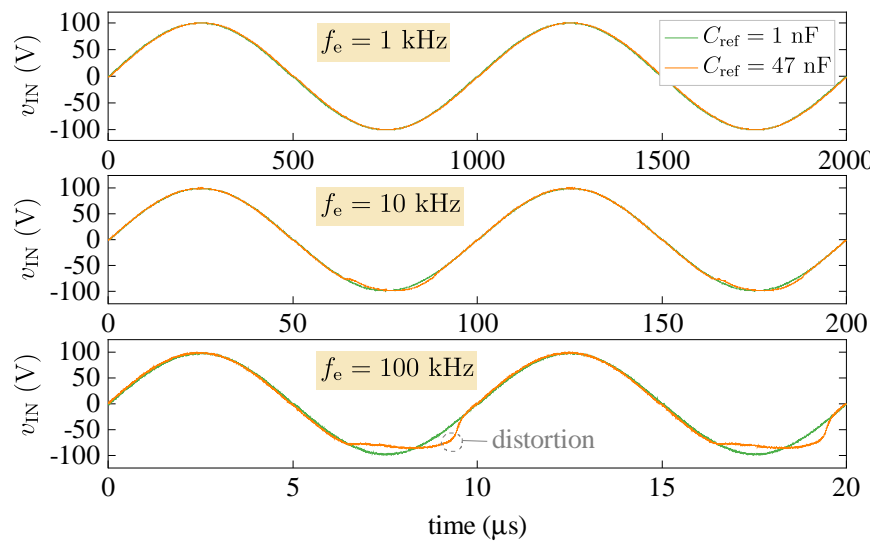

Fig. 7. Experimental waveforms of $v_{\mathrm{IN}}$ for the IPP60R060P7 MOSFET (Si$\mathrm{SJ})$ for different excitation frequencies. $v_{\mathrm{IN}}$ gets distorted when $C_{\text {ref }}$ is large.

of $C_{\text {ref }}=1 \mathrm{nF}\left(\approx 0.025 \times\left. C_{\mathrm{oss}}\right|_{v_{\mathrm{DS}}=0}\right)$, no distortion occurs as expected; while a clear distortion in $v_{\mathrm{IN}}$ appears for the case of $C_{\text {ref }}=47 \mathrm{nF}\left(\approx 1 \times\left. C_{\mathrm{oss}}\right|_{v_{\mathrm{DS}}=0}\right)$.

The distortion increases with increasing $f_{\mathrm{e}}$ as the load impedance gets further lowered. Therefore, for a DUT with large $C_{\mathrm{oss}}, f_{\mathrm{e}}$ should be chosen adequately low so that the amplifiers output power $\left(P_{\text {out }} \propto f_{\mathrm{e}} \cdot G\right)$ capability is respected. If the power capability is exceeded, then the gain $G$, and hence the available voltage output $v_{\mathrm{A}}=G \cdot v_{\mathrm{S}}$ will reduce.

\section{Calculation of $C_{\text {ref }}$}

The selection of $C_{\text {ref }}$ is of vital importance for the correct operation of the Sawyer-Tower circuit [17], [18], [20]. Here we present a new equation to calculate $C_{\text {ref }}$ based on design requirements. We assume that there is no distortion in $v_{\mathrm{IN}}$ due to the slew-rate limitations, and that $C_{\text {ref }}$ is ideal and linear.

To derive an equation for the value of $C_{\text {ref }}$, consider $C_{\mathrm{o}}$ characterisation of a DUT for a $v_{\mathrm{DS}}$ swing of $V_{\mathrm{DS}-\mathrm{min}}=-V_{\mathrm{FW}}$ to $V_{\mathrm{DS}-\mathrm{max}}$, and an input voltage swing of $\pm V_{\mathrm{p}}$. Considering the load-side circuit; and at $v_{\mathrm{DS}}=V_{\mathrm{DS}-\max }$, the following holds:

$$
+V_{\mathrm{p}}=V_{\mathrm{BIAS}}+V_{\text {ref+ }}+V_{\mathrm{DS}-\max } .
$$

This equation can be further solved by realising that in steady state, $V_{\mathrm{BIAS}}=V_{\mathrm{REF}}=\left(-V_{\mathrm{p}}+V_{\mathrm{FW}}\right)+V_{\text {ref-, }}$, where $-V_{\mathrm{FW}}$ is the device's dc voltage drop during reverse conduction (see Section IV-F). Substituting this into (6) gives,

$$
2 V_{\mathrm{p}}=V_{\mathrm{FW}}+V_{\mathrm{DS}-\mathrm{max}}+V_{\text {ref- }}+V_{\text {ref+- }} .
$$

The term " $V_{\text {ref- }}+V_{\text {reft }}$ " can be substituted by using (8) and (9), which are easily derived from (2). Simplifying, we get an essential equation in (10) to calculate the value of $C_{\text {ref }}$ required for a given $v_{\mathrm{DS}}$ swing of $V_{\mathrm{DS}-\mathrm{max}}$.

$$
\begin{aligned}
Q_{\mathrm{o}-\text { max }} & =C_{\text {ref }}\left(V_{\text {ref }+}-\left.v_{\text {ref }}\right|_{v_{\mathrm{DS}}=0}\right) \\
Q_{\mathrm{o}-\text { min }} & =C_{\text {ref }}\left(-V_{\text {ref- }}-\left.v_{\text {ref }}\right|_{v_{\mathrm{DS}}=0}\right) \\
C_{\text {ref }} & =\frac{Q_{\text {o-max }}-Q_{\text {o-min }}}{2 V_{\mathrm{p}}-V_{\mathrm{DS}-\max }-V_{\mathrm{FW}}}
\end{aligned}
$$

Here $Q_{\mathrm{o}-\max }$ and $Q_{\mathrm{o}-\mathrm{min}}$ are the minimum and maximum charge stored in the DUT. For practical cases, $Q_{\mathrm{o}-\min }$ can be assumed 


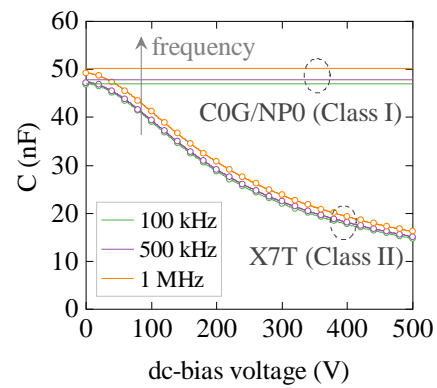

(a)

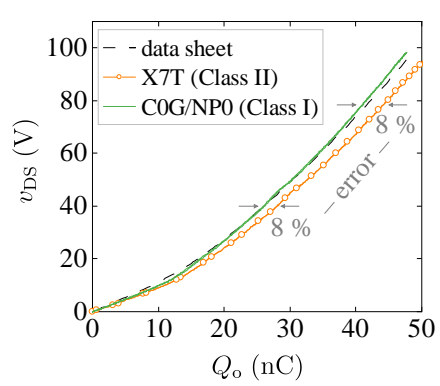

(b)
Fig. 8. (a) Capacitance vs bias voltage of $C_{\text {ref }}$ measured with a Keysight B1505A curve tracer, and (b) experimental $Q_{0}$ curves for an EPC2001C transistor at $f_{\mathrm{e}}=100 \mathrm{kHz}$ using same $C_{\text {ref. }}$. A Class I C0G/NP0 capacitor (TDK CGA8R4NP02J473J320KA) and a Class II X7T capacitor (TDK CGA5L1X7T2J473K160AC) with nominal values of $47 \mathrm{nF}$ are compared.

to be negligible compared to $Q_{\text {o-max }}$ : the small-signal $Q_{\text {oss-max }}$ that can be easily estimated from data-sheet $C_{\text {oss }}$ curves is a good first approximation for $Q_{\mathrm{o}-\max }$. For instance, for an EPC $2001 \mathrm{C}$ device subjected to $V_{\text {DS-max }}=50 \mathrm{~V}$, (where $Q_{\mathrm{o}-\max } \approx$ $30 \mathrm{nC}$ at $50 \mathrm{~V}), C_{\text {ref }}$ should be higher than $600 \mathrm{pF}$ if $V_{\mathrm{p}}$ is limited to $50 \mathrm{~V}$.

\section{Selecting the Type of $C_{\mathrm{ref}}$}

There are mainly two commonly used Multi-Layer Ceramic Capacitor (MLCC) types available in the market that are classified upon their dielectric class (of EIA standard): Class I and Class II. Class I dielectric based capacitors, also known as $\mathrm{C} 0 \mathrm{G} / \mathrm{NP0}$ temperature compensating capacitors, are based on non-ferroelectric materials and exhibit a fixed capacitance with the bias-voltage: measured characteristics for this type of capacitor is shown in Fig. 8a. On the other hand, the capacitance of Class II capacitors (e.g. X7R, X7T and X5R types) decreases with the bias-voltage as shown in Fig. 8a.

Fig. 8b shows experimental $Q_{\text {o }}$ curves for an EPC2001C transistor using both types of capacitors as $C_{\text {ref }}$ (nominal value $=47 \mathrm{nF}$ ), where the dashed black line denotes the small-signal $Q_{\text {oss }}$ curve. The curve for the X7T type shows a clear deviation from the C0G/NP0 type: an $8 \%$ error is observed in $Q_{\mathrm{o}}$ where the deviation reaches up to $3.7 \mathrm{nC}$ for $v_{\mathrm{DS}}=100 \mathrm{~V}$. C0G/NP0 (Class I) is, thus, the preferred type because $C_{\text {ref }}$ should be independent of $V_{\mathrm{BIAS}}$ throughout the whole $v_{\mathrm{DS}}$ range.

\section{E. Frequency Dependence of $C_{\mathrm{ref}}$}

Although COG/NP0 type has a fixed capacitance throughout the voltage range, both its capacitance and equivalent series resistance, $R_{\mathrm{ESR}}$, are frequency dependent. Thus for a given $C_{\text {ref }}$ value and type, $f_{\mathrm{e}}$ has an upper limit.

Measured impedance and capacitance values of two different $\mathrm{C} 0 \mathrm{G} / \mathrm{NP} 0$ capacitors $\left(C_{1}\right.$ and $\left.C_{2}\right)$ are shown in Fig. 9: their impedances exhibit significant decrease when $f_{\mathrm{e}}$ approaches the Self-Resonant Frequency (SRF) of the capacitor. This is due to the increase of both capacitance and $R_{\mathrm{ESR}}$ with $f_{\mathrm{e}}$ up to the SRF. This results in an overall increase in the load current,

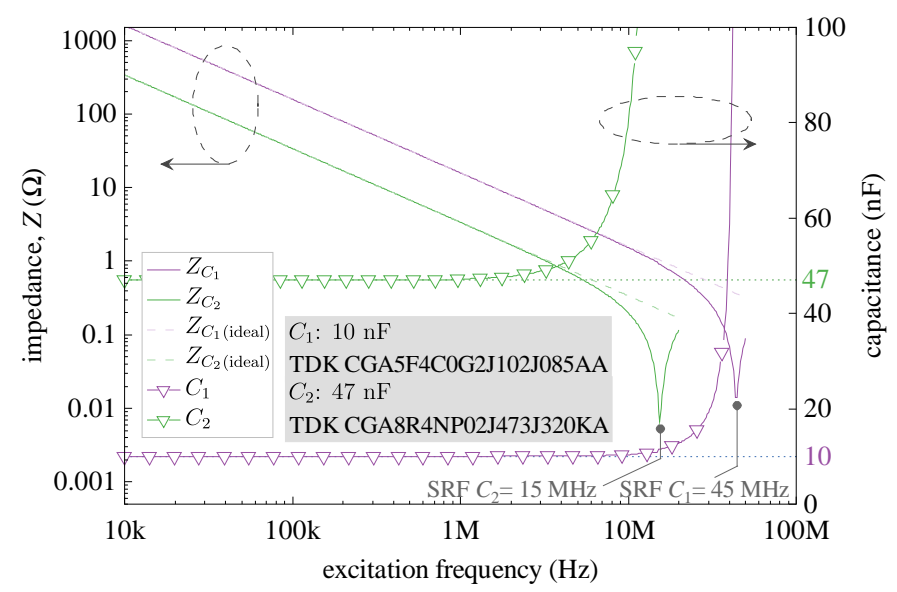

Fig. 9. Variation of impedance and capacitance of two C0G/NP0 capacitors $\left(C_{1}\right.$ of $10 \mathrm{nF}$ and $C_{2}$ of $47 \mathrm{nF}$ ) measured with Keysight E4990A impedance analyser. The actual impedance values $\left(Z_{C_{1}}\right.$ and $\left.Z_{C_{2}}\right)$ starts to deviate from their ideal ones (indicated by dashed lines) when approaching their SRFs.

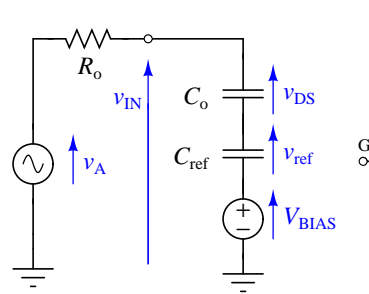

(a)

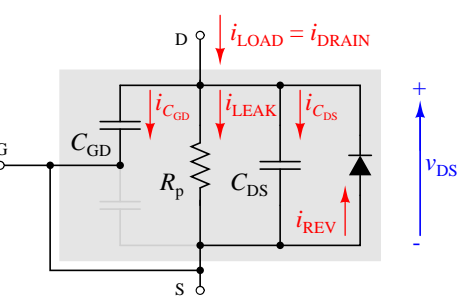

(b)
Fig. 10. (a) Sawyer-Tower circuit in steady state where $v_{\mathrm{REF}}=v_{\text {ref }}+V_{\mathrm{BIAS}}$, and (b) a model of the DUT showing the leakage current $i_{\text {LEAK }}$.

and hence, an increase in the voltage drop across $R_{\mathrm{ESR}}$. The measured $v_{\text {ref }}$, in steady state, is now given by (11).

$$
\left.v_{\text {ref }}\right|_{\text {measured }}=\left.v_{\text {ref }}\right|_{\text {actual }}+i_{\mathrm{LOAD}} \cdot R_{\mathrm{ESR}}
$$

The term $i_{\mathrm{LOAD}} \cdot R_{\mathrm{ESR}}$ adds an error to the calculated $Q_{\mathrm{o}}$ value that gets higher as $f_{\mathrm{e}}$ approaches SRF. Operation close to the SRF also introduces a deviation of $C_{\text {ref }}$ from its nominal value, adding further to the $Q_{\mathrm{o}}$ estimation error. A discussion on the optimal $f_{\mathrm{e}}$ range is given in Section $\mathrm{V}$, showing the upper bound for $f_{\mathrm{e}}$ when selecting a commercial capacitor.

\section{F. Reverse Conduction of the DUT}

The Sawyer-Tower circuit is based on the fundamental assumption that the current through $C_{\text {ref }}$ and the device's $C_{\mathrm{o}}$ are always equal in steady-state, meaning that there is no reverse conduction (third-quadrant operation) of the DUT [15], [20]. Our investigations show that this does not hold true for all the design/operating conditions.

To elucidate, we consider that the device has reached steady state, where the dc bias in $C_{\text {ref }}$ is given in (12), in which $V_{\mathrm{FW}}$ is assumed to be a fixed dc voltage drop independent of the level of reverse current.

$$
V_{\mathrm{BIAS}}=V_{\mathrm{REF}}=\left(-V_{\mathrm{p}}+V_{\mathrm{FW}}\right)+V_{\text {ref- }}
$$

The corresponding circuit is given in Fig. 10a, where we get,

$$
v_{\mathrm{DS}}=v_{\mathrm{IN}}-v_{\mathrm{ref}}-V_{\mathrm{BIAS}} .
$$




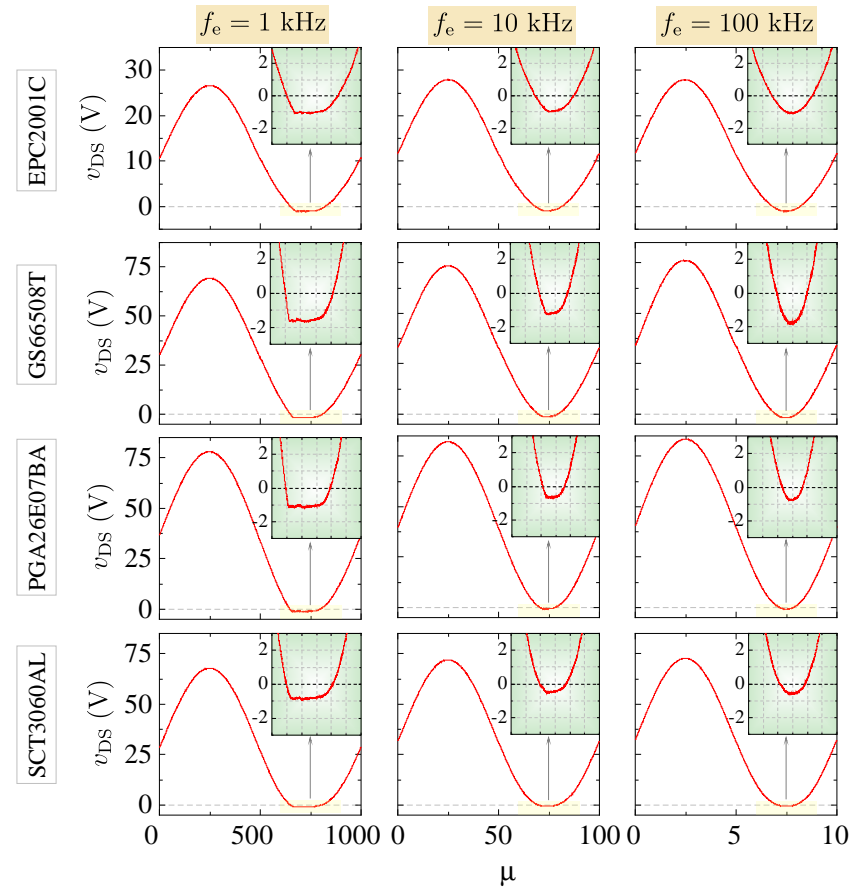

Fig. 11. Experimental waveforms of $v_{\mathrm{DS}}$ showing steady-state reverse conduction for DUTs: GaN HEMTs; EPC2001C, GS66508T, PGA26E07BA and $\mathrm{SiC}$ device SCT3060AL. Negative clipping of $v_{\mathrm{DS}}$ is clearly seen in all the cases for $f_{\mathrm{e}}=1 \mathrm{kHz}$ and $10 \mathrm{kHz}$. $C_{\mathrm{ref}}$ of $1 \mathrm{nF}$ was used.

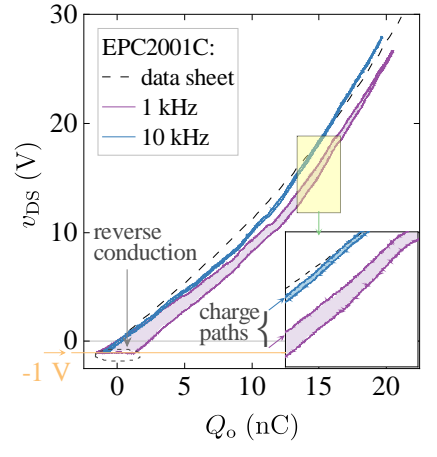

(a)

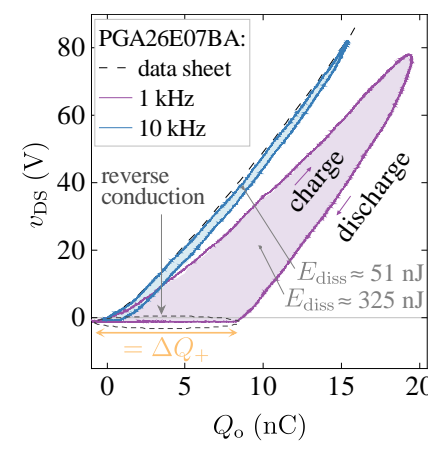

(b)
Fig. 12. Experimental $v_{\text {DS }}$ vs $Q_{0}$ curves for (a) EPC 2001C, and (b) PGA26E07BA transistors, showing hysteresis paths and $E_{\text {diss }}$ losses that are not due to $C_{0}$, but due to an artefact of the steady-state reverse conduction of the DUT. For the PGA26E07BA device, at $10 \mathrm{kHz}$, this creates an $E_{\mathrm{diss}}$ loss of $51 \mathrm{~nJ}$, while it increases up to $325 \mathrm{~nJ}$ at $1 \mathrm{kHz}$.

Applying (13) for the negative peak of $v_{\mathrm{IN}}$, and substituting $V_{\mathrm{BIAS}}$ from (12), we get $v_{\mathrm{DS}}=-V_{\mathrm{FW}}$. This shows that the reverse conduction is inhibited as long as $v_{\mathrm{DS}} \geq-V_{\mathrm{FW}}$.

However, clipping of $v_{\mathrm{DS}}$ at $-V_{\mathrm{FW}}$ level was experimentally observed, indicating steady-state reverse conduction of the DUT. This effect is shown in Fig. 11 for several transistors. The three GaN HEMTs show clipped $v_{\text {DS }}$ values of $-1.1 \mathrm{~V}$, $-1.8 \mathrm{~V}$ and $-1.2 \mathrm{~V}$ respectively for $f_{\mathrm{e}}=1 \mathrm{kHz}$, while the $\mathrm{SiC}$ device shows clipping at $-0.9 \mathrm{~V}$. The clipping period increases with decreasing $f_{\mathrm{e}}$ as seen in Fig. 11 for $f_{\mathrm{e}}=1$ and $10 \mathrm{kHz}$.

The effect of steady-state reverse conduction on the SawyerTower technique can be directly observed in Fig. 12, that shows the resulting $v_{\text {DS }}$ vs $Q_{\mathrm{o}}$ curves. For both transistors, $Q_{\mathrm{o}}$ curves show a flat region at the bottom of the discharge

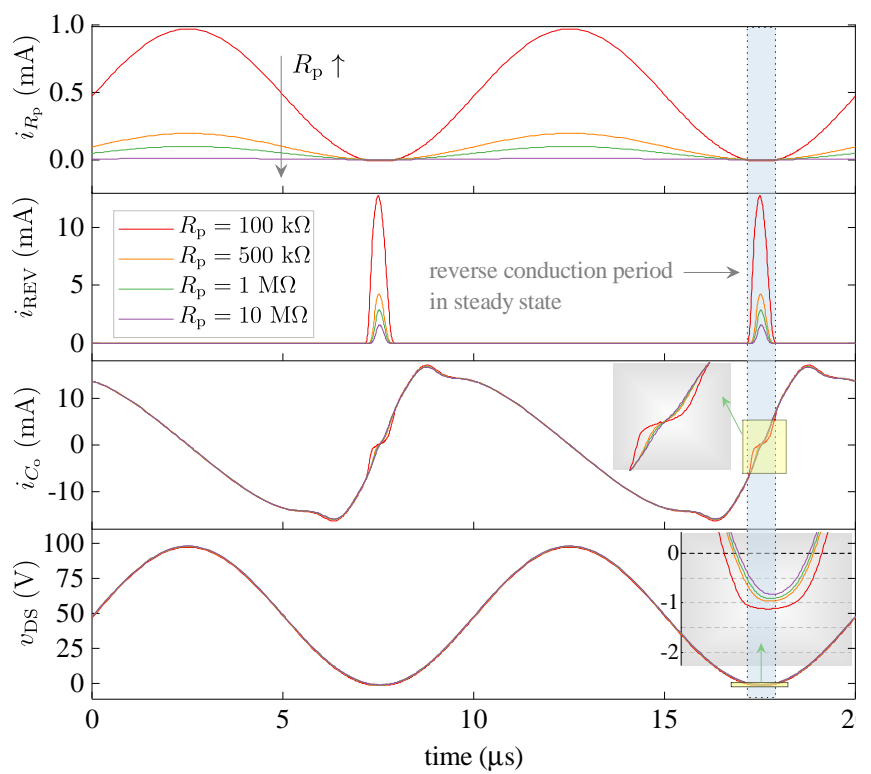

Fig. 13. LTspice simulation results showing the effect of device leakage (by changing $R_{\mathrm{p}}$ ) on creating a reverse conduction period in steady state, in the Sawyer-Tower circuit. $v_{\text {DS }}$ clipping at $-1.2 \mathrm{~V}$ shows clear reverse conduction. The DUT consists of an EPC 2001C device model and an external resistance $R_{\mathrm{p}}$, placed across the device's drain and source, to create different leakage levels. $f_{\mathrm{e}}=100 \mathrm{kHz}, v_{\mathrm{A}}= \pm 50 \mathrm{~V}, C_{\mathrm{ref}}=47 \mathrm{nF}$ and $R_{\mathrm{o}}=50 \Omega$.

path, that proves that $C_{\mathrm{o}}$ stops discharging and the DUT starts to conduct in reverse mode. During this period the assumption $Q_{\mathrm{o}} \propto C_{\text {ref }} \cdot v_{\text {ref }}$ is no longer valid, leading to false conclusions on existence of hysteresis for $Q_{\mathrm{o}}$. For example, for the $\mathrm{GaN}$ device in Fig. $12 \mathrm{~b}$, an $E_{\text {diss }}$ of $51 \mathrm{~nJ}$ is observed at $10 \mathrm{kHz}$. It increases up to a significant $325 \mathrm{~nJ}$ at $1 \mathrm{kHz}$, where the underlying reasons are discussed in Section V-C. These losses should not be considered as due to $C_{\mathrm{o}}$.

This reverse conduction happens because $C_{\text {ref }}$ accumulates some positive dc charge, $\Delta Q_{+}$, that results in a slight positive addition to its steady-state dc bias. The new bias can be written as $V_{\mathrm{BIAS}}+\Delta Q_{+} \cdot C_{\text {ref }}$, which results in $v_{\mathrm{DS}}=-V_{\mathrm{FW}}-\Delta Q_{+}$. $C_{\text {ref }}<-V_{\mathrm{FW}}$, allowing reverse conduction to take place. The small reverse currents, indicated by the small reverse voltages, lead to the conclusion that the slight dc bias $\Delta Q_{+} \cdot C_{\text {ref }}$ is related to the off-state drain-source leakage of the DUT.

To support this theory, a simulation was carried out in which the leakage was modelled by a resistance $R_{\mathrm{p}}$, placed across the device's drain and source, as shown in Fig. 10b. Results for an EPC2001C device are shown in Fig. 13, where $R_{\mathrm{p}}$ is changed from $100 \mathrm{k} \Omega$ to $10 \mathrm{M} \Omega$ to model devices with highleakage currents $(1 \mathrm{~mA})$ and low-leakage currents $(50 \mu \mathrm{A})$. For low $R_{\mathrm{p}}$ values, the leakage current $\left(i_{\mathrm{LEAK}}=i_{R_{\mathrm{p}}}\right)$ is large enough to cause a clipping of $v_{\mathrm{DS}}$ at $-1.1 \mathrm{~V}$, as shown in the zoomed inset. The reverse conduction is also confirmed by the flattening of $C_{\mathrm{o}}$ current, $i_{C_{\mathrm{o}}}$, during this period.

Therefore, the reverse conduction due to device leakage causes an additional DUT loss that could be misinterpreted as $Q_{\mathrm{o}}$ hysteresis loss, thus, compromising the use of the SawyerTower technique. This problem can be mitigated by correctly choosing the range of $f_{\mathrm{e}}$ as discussed in Section V-C. 


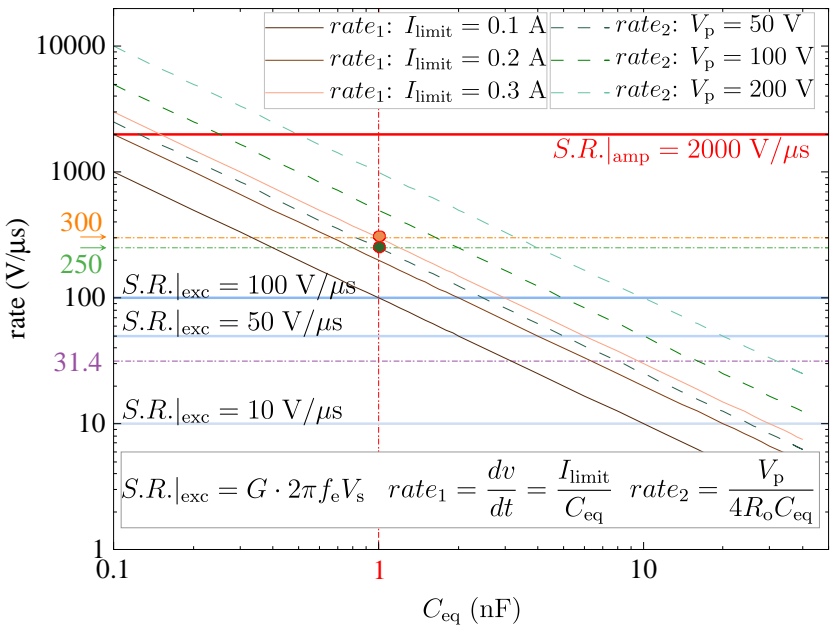

Fig. 14. Variation of rate 1 (in solid diagonal lines for different $I_{\text {limit }}$ ), and rate $_{2}$ (in dashed diagonal lines for different $V_{\mathrm{p}}$, with $R_{\mathrm{o}}$ fixed at $50 \Omega$ ) with $C_{\mathrm{eq}}$. Solid blue lines show practical $S . R$. $\left.\right|_{\mathrm{exc}}$ values while the solid red line shows $S . R .\left.\right|_{\text {amp }}$ for WMA-300 amplifier.

\section{Discussion And Design ReCOMmendations}

\section{A. Voltage Amplifier Selection and Slew-Rate Limitations}

For the correct implementation of the Sawyer-Tower circuit, the amplifier slew-rate should satisfy (3). At the same time, the circuit parameters should be chosen such that the dominant load slew-rate, S.R. $\left.\right|_{\text {dominant }}$, is higher than S.R. $\left.\right|_{\text {exc }}$.

$$
S . R .\left.\right|_{\mathrm{exc}}<S . R .\left.\right|_{\mathrm{dominant}}<S . R .\left.\right|_{\mathrm{amp}}
$$

Fig. 14 provides a quick reference chart to evaluate whether the circuit satisfies the slew-rate conditions of (14) for a given $C_{\text {eq }}$ value. An example of a good selection is given for an EPC2001C transistor, tested with a WMA-300 amplifier of S.R. $\left.\right|_{\mathrm{amp}}=2000 \mathrm{~V} / \mu \mathrm{s}$ and $I_{\text {limit }}=300 \mathrm{~mA}$, shown as solid red and orange lines in Fig. 14, respectively: consider a sinusoidal excitation of $f_{\mathrm{e}}=100 \mathrm{kHz}, V_{\mathrm{s}}=1 \mathrm{~V}, G=50, R_{\mathrm{o}}=50 \Omega$, and $C_{\text {ref }}=47 \mathrm{nF}$. Then S.R. $\left.\right|_{\mathrm{exc}}$ is calculated to be $31.4 \mathrm{~V} / \mu \mathrm{s}$ $<S . R$. $\left.\right|_{\mathrm{amp}}$. According to Fig. $5 \mathrm{a}, C_{\mathrm{eq}}$ in the low $v_{\mathrm{DS}}$ range is 1 $\mathrm{nF}$. Then, rate $_{1}$ and rate $_{2}$ are calculated as 300 and $250 \mathrm{~V} / \mu \mathrm{s}$, respectively (equations given in Fig. 14). Thus, S.R. $\left.\right|_{\text {dominant }}=$ $250 \mathrm{~V} / \mu \mathrm{s}$, and thus, (14) is satisfied. On the other hand, if $f_{\mathrm{e}}$ is increased to $1 \mathrm{MHz}$, with everything else unchanged, then $S . R .\left.\right|_{\mathrm{exc}}=314 \mathrm{~V} / \mu \mathrm{s}$, and (14) is no longer satisfied.

\section{B. Selection of $C_{\text {ref }}$}

A map of possible selections for $C_{\text {ref }}$, based on (10), for a given $V_{\mathrm{p}}$ is shown in Fig. 15. Four different families of curves for $V_{\mathrm{p}}$ are chosen between 50-300 V. Additionally, five $Q_{\mathrm{o}-\max }$ values between $5-120 \mathrm{nC}$ are considered, that corresponds to commercial MOSFETs and GaN HEMTs. For instance, consider $V_{\mathrm{p}}=100 \mathrm{~V}$ and a $50 \%$ voltage swing across a DUT with $Q_{\text {o-max }}=50 \mathrm{nC}$ at $V_{\text {DS-max }}=100 \mathrm{~V}$ (marked with a red circle): the optimum $C_{\text {ref }}$ is then calculated as $500 \mathrm{pF}$ (assume $V_{\mathrm{FW}} \approx 0$ ).

For a given C0G/NP0 MLC capacitor, $f_{\mathrm{e}}$ should be chosen in the flat part of the $C$ vs $f_{\mathrm{e}}$ curve (see Fig. 9). This range

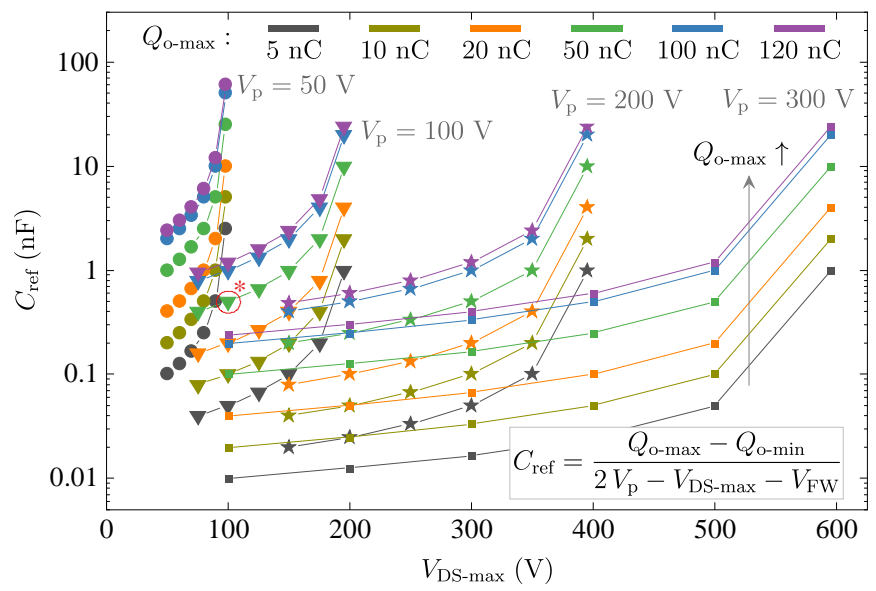

Fig. 15. Selection chart of $C_{\text {ref }}$ value for a required $V_{\text {DS-max }}$ based on the input voltage range $V_{\mathrm{p}}$ and device's $Q_{\mathrm{o}-\max } \cdot Q_{\mathrm{o}-\min } \approx 0$ for practical cases.

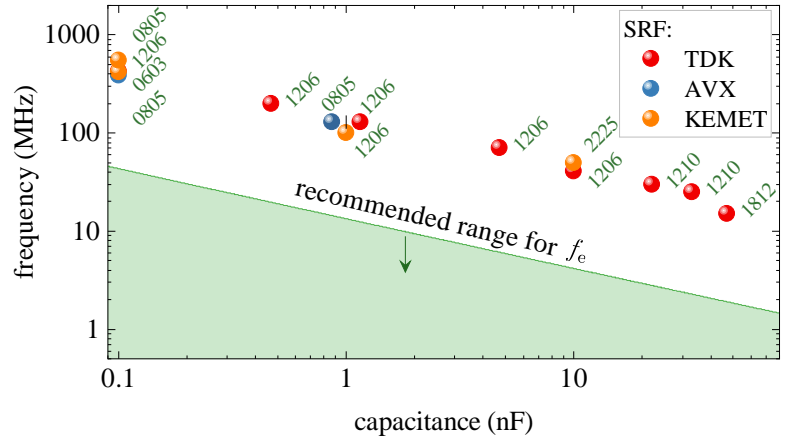

Fig. 16. Self resonant frequency (solid dots) vs capacitance for commercial C0G/NP0 MLC capacitors (500/630 V): green labels indicate the package.

normally extends up to SRF/10. The acceptable range of $f_{\mathrm{e}}$ values for a selection of commercial capacitors is shown in Fig. 16.

\section{Minimizing Steady-State Reverse Conduction of the DUT}

To minimize the effects of the steady-state reverse conduction, $f_{\mathrm{e}}$ should be chosen such that the resulting extra positive dc charge, $\Delta Q_{+}$, due to leakage is at least two orders of magnitudes lower compared to the device's reported $Q_{\mathrm{o}}$ range to have an error less than $1 \%$.

For the worst case, where the leakage current is at maximum, $I_{\text {LEAK-max }}$, the charge $\Delta Q_{+}$is written as in (15), where $T_{\mathrm{e}}=1 / f_{\mathrm{e}}$, and $T_{\mathrm{rev}}$ is the duration of the reverse conduction.

$$
\Delta Q_{+}=I_{\text {LEAK-max }} \cdot\left(T_{\mathrm{e}}-T_{\text {rev }}\right)
$$

For all practical purposes, we can assume $T_{\mathrm{e}} \gg T_{\text {rev }}$, and thus,

$$
\Delta Q_{+} \propto \frac{I_{\text {LEAK-max }}}{f_{\mathrm{e}}} .
$$

This reveals that $\Delta Q_{+}$increases with decreasing $f_{\mathrm{e}}$. For low $f_{\mathrm{e}}, \Delta Q_{+}$becomes comparable to devices' $Q_{\mathrm{o}}$ values and could cause significant errors in estimated $Q_{\mathrm{o}}$. This is illustrated in Fig. 17, where $\Delta Q_{+} \approx I_{\text {LEAK-max }} / f_{\mathrm{e}}$ is used with practical device leakage currents. For example, if a device with $I_{\text {LEAK-max }}=100 \mu \mathrm{A}$ is subjected to a $Q_{\mathrm{o}}$ swing of $100 \mathrm{nC}$ (dashed orange line), the error changes from $1 \%$ to $10 \%$ when $f_{\mathrm{e}}$ changes from $100 \mathrm{kHz}$ to $10 \mathrm{kHz}$ (marked with red circles). 


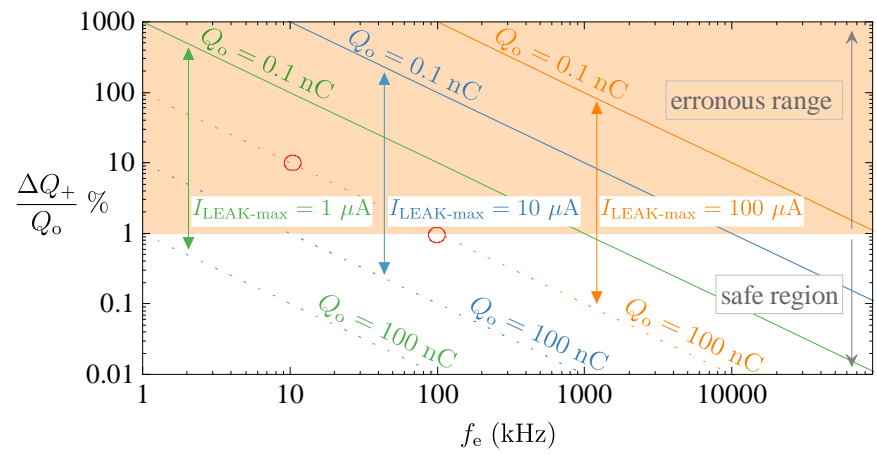

Fig. 17. The variation of the ratio between $\Delta Q_{+}$and device $Q_{0}$ values, with $f_{\mathrm{e}}$. For each case of $I_{\text {LEAK-max }}$, the dashed and solid lines correspond to a change of $Q_{\mathrm{o}}$ from 100 to $0.1 \mathrm{nC}$, respectively.

\section{CONCLUSiOnS}

A detailed analysis of the Sawyer-Tower circuit is presented highlighting key design factors. A new equation for the chargevoltage curve variation is introduced. A complete treatment on the selection of the reference capacitor was presented with design recommendations, with a new equation to correctly select its value for a given operating condition. A clear steadystate reverse conduction was proved for the Sawyer-Tower technique, highlighting its adverse effects on the technique and results. We showed that this effect can be minimized by choosing the excitation frequency such that the leakage-related build-up charge is at least two orders of magnitudes lower compared to device's $Q_{\mathrm{o}}$.

The importance of fully identifying the validity of the measurement methods, and the corresponding mathematical estimation techniques, used in characterizing/modelling the $C_{\mathrm{o}}$ (or $Q_{\mathrm{o}}$ ) behaviour and related losses should be emphasized. Ongoing work focuses on the following: 1) effects of the excitation type on the behaviour of large-signal $C_{\mathrm{o}}$ and related losses; 2) circuit-level representations for $C_{\mathrm{o}}$ of different device structures to model the reported large-signal losses.

\section{ACKNOWLEDGMENT}

The authors would like to thank Pietro Bianco from Linktronix AG for his kind technical advice and support.

\section{REFERENCES}

[1] K. J. Chen, O. Häberlen, A. Lidow, C. 1 Tsai, T. Ueda, Y. Uemoto, and Y. Wu, "GaN-on-Si Power Technology: Devices and Applications," IEEE Transactions on Electron Devices, vol. 64, no. 3, pp. 779-795, Mar. 2017.

[2] M. Ishida, T. Ueda, T. Tanaka, and D. Ueda, "GaN on Si Technologies for Power Switching Devices," IEEE Transactions on Electron Devices, vol. 60, no. 10, pp. 3053-3059, Oct. 2013.

[3] A. Lidow, J. Strydom, M. de Rooij, and D. Reusch, GaN Transistors for Efficient Power Conversion, 2nd ed. Wiley, Sep. 2014.

[4] E. A. Jones, F. F. Wang, and D. Costinett, "Review of Commercial GaN Power Devices and GaN-Based Converter Design Challenges," IEEE Journal of Emerging and Selected Topics in Power Electronics, vol. 4, no. 3, pp. 707-719, Sep. 2016

[5] S. Nagai, Y. Kawai, O. Tabata, S. Choe, N. Negoro, and T. Ueda, "A high-efficient driving isolated Drive-by-Microwave half-bridge gate driver for a GaN inverter," in 2016 IEEE Applied Power Electronics Conference and Exposition (APEC), Mar. 2016, pp. 2051-2054.
[6] N. Fichtenbaum, M. Giandalia, S. Sharma, and J. Zhang, "Half-Bridge GaN Power ICs: Performance and Application," IEEE Power Electronics Magazine, vol. 4, no. 3, pp. 33-40, Sep. 2017.

[7] W. Zhang, F. Wang, D. J. Costinett, L. M. Tolbert, and B. J. Blalock, "Investigation of Gallium Nitride Devices in High-Frequency LLC Resonant Converters," IEEE Transactions on Power Electronics, vol. 32, no. 1, pp. 571-583, Jan. 2017.

[8] R. Elferich, "General ZVS half bridge model regarding nonlinear capacitances and application to LLC design," in 2012 IEEE Energy Conversion Congress and Exposition (ECCE), Sep. 2012, pp. 4404-4410.

[9] J. B. Fedison, M. Fornage, M. J. Harrison, and D. R. Zimmanck, "Coss related energy loss in power MOSFETs used in zero-voltage-switched applications," in 2014 IEEE Applied Power Electronics Conference and Exposition - APEC 2014, Mar. 2014, pp. 150-156.

[10] J. Roig and F. Bauwens, "Origin of Anomalous Coss Hysteresis in Resonant Converters With Superjunction FETs," IEEE Transactions on Electron Devices, vol. 62, no. 9, pp. 3092-3094, Sep. 2015.

[11] A. Chiarenza, A. Raciti, R. Scollo, and A. Scuto, "Determination of the power losses due to the nonlinear coss capacitance of SJ MOSFETs submitted to voltage transients in ZVS applications," in IECON 2017 - 43rd Annual Conference of the IEEE Industrial Electronics Society, Oct. 2017, pp. 1089-1094.

[12] J. Roig, G. Gomez, F. Bauwens, B. Vlachakis, M. R. Rogina, A. Rodriguez, and D. G. Lamar, "High-accuracy modelling of ZVS energy loss in advanced power transistors," in 2018 IEEE Applied Power Electronics Conference and Exposition (APEC), Mar. 2018, pp. 263-269.

[13] D. Bura, T. Plum, J. Baringhaus, and R. W. D. Doncker, "Hysteresis Losses in the Output Capacitance of Wide Bandgap and Superjunction Transistors," in 2018 20th European Conference on Power Electronics and Applications (EPE'18 ECCE Europe), Sep. 2018, pp. P.1-P.9.

[14] M. Guacci, M. Heller, D. Neumayr, D. Bortis, J. W. Kolar, G. Deboy, C. Ostermaier, and O. Häberlen, "On the Origin of the Coss -Losses in Soft-Switching GaN-on-Si Power HEMTs," IEEE Journal of Emerging and Selected Topics in Power Electronics, vol. 7, no. 2, pp. 679-694, Jun. 2019.

[15] Z. Tong, G. Zulauf, J. Xu, J. D. Plummer, and J. Rivas-Davila, "Output Capacitance Loss Characterization of Silicon Carbide Schottky Diodes," IEEE Journal of Emerging and Selected Topics in Power Electronics, vol. 7, no. 2, pp. 865-878, Jun. 2019.

[16] G. Zulauf, S. Park, W. Liang, K. Surakitbovorn, and J. M. R. Davila, "Coss Losses in $600 \mathrm{~V}$ GaN Power Semiconductors in Soft-Switched, High- and Very-High-Frequency Power Converters," IEEE Transactions on Power Electronics, pp. 1-1, 2018.

[17] J. B. Fedison and M. J. Harrison, "COSS hysteresis in advanced superjunction MOSFETs," in 2016 IEEE Applied Power Electronics Conference and Exposition (APEC), Mar. 2016, pp. 247-252.

[18] A. Raciti, S. A. Rizzo, N. Salerno, G. Susinni, R. Scollo, and A. Scuto, "Modeling the Hysteresis Power Losses of the Output Parasitic Capacitance in Super Junction MOSFETs," in 2018 International Symposium on Power Electronics, Electrical Drives, Automation and Motion (SPEEDAM), Jun. 2018, pp. 527-532.

[19] C. B. Sawyer and C. H. Tower, "Rochelle Salt as a Dielectric," Phys. Rev., vol. 35, no. 3, pp. 269-273, Feb. 1930.

[20] G. Zulauf, Z. Tong, J. D. Plummer, and J. M. Rivas-Davila, "Active Power Device Selection in High- and Very-High-Frequency Power Converters," IEEE Transactions on Power Electronics, vol. 34, no. 7, pp. 6818-6833, Jul. 2019.

[21] G. D. Zulauf, J. Roig-Guitart, J. D. Plummer, and J. M. Rivas-Davila, "Coss Measurements for Superjunction MOSFETs: Limitations and Opportunities," IEEE Transactions on Electron Devices, vol. 66, no. 1, pp. 578-584, Jan. 2019.

[22] Alpha and Omega Semiconductor, "MOS-007: Power MOSFET Basics,", http://www.aosmd.com/applications/notes/mosfets, 2009.

[23] M. H. Rashid, Ed., Power Electronics Handbook: Devices, Circuits, and Applications Handbook, 3rd ed. Burlington, MA: Elsevier, 2011.

[24] D. Costinett, D. Maksimovic, and R. Zane, "Circuit-Oriented Treatment of Nonlinear Capacitances in Switched-Mode Power Supplies," IEEE Transactions on Power Electronics, vol. 30, no. 2, pp. 985-995, Feb. 2015.

[25] R. Miftakhutdinov, "Analysis and practical method of determining WBG FET switching losses associated with nonlinear coss," in 2017 IEEE Applied Power Electronics Conference and Exposition (APEC), Mar. 2017, pp. 974-978. 
[26] Impedance Measurement Handbook, 6th ed. Keysight Technologies, Nov. 2016.

[27] A. Wadsworth, The Parametric Measurement Handbook. Keysight Technologies, Dec. 2017.

[28] M. S. Nikoo, A. Jafari, N. Perera, and E. Matioli, "Measurement of Large-Signal Coss and Coss Losses of Transistors Based on Nonlinear Resonance," IEEE Transactions on Power Electronics, pp. 1-1, 2019.

[29] D. N. Pattanayak and O. G. Tornblad, "Large-signal and small-signal output capacitances of super junction MOSFETs," in 2013 25th International Symposium on Power Semiconductor Devices IC's (ISPSD), May 2013, pp. 229-232.

[30] R. Hou, J. Lu, and D. Chen, "Parasitic capacitance Eqoss loss mechanism, calculation, and measurement in hard-switching for GaN HEMTs,' in 2018 IEEE Applied Power Electronics Conference and Exposition (APEC), Mar. 2018, pp. 919-924. 